\title{
ANÁLISE DOS IMPACTOS SOCIOECONÔMICOS E AMBIENTAIS DA EXPANSÃO DA CANA-DE-AÇÚCAR NA BACIA DO RIO MEIA PONTE, GOIÁS
}

\author{
ANÁLISIS DEL IMPACTO SOCIOECONÓMICO Y AMBIENTAL DE LA \\ AMPLIACIÓN DE LA CAÑA DE AZÚCAR EN LA CUENCA MEDIA DEL PUENTE
}

\section{ANALYSIS OF SOCIO-ECONOMIC AND ENVIRONMENTAL IMPACTS OF EXPANSION OF SUGAR CANE RIVER BASIN IN HALF BRIDGE}

\author{
Renato Araújo TEIXEIRA ${ }^{1}$ \\ Maria Socorro Duarte da Silva COUTO
}

\begin{abstract}
RESUMO: O Cerrado, o segundo maior bioma da América do Sul, ocupa uma área de 2.039.387 km², abrange 12 estados, dentre eles o estado de Goiás. É reconhecido como sendo um dos 34 hotspots de biodiversidade no mundo, tanto por seus aspectos naturais, quanto pela intensa ocupação agropastoril, que o transformou na principal fronteira de expansão agrícola brasileira. A crescente demanda por fontes alternativas de energia renovável exige uma expansão acelerada e pouco planejada, principalmente em áreas ocupadas pelo bioma Cerrado. Em particular, a região da bacia do Rio Meia Ponte destaca-se pela complexidade desse problema, que pode resultar em significativas consequências negativas, tanto no âmbito ambiental quanto no socioeconômico. Desta forma, este artigo tem como objetivo central, apresentar os principais resultados das análises dos impactos sociais, econômicos e ambientais provocados pela intensificação/expansão da cana-de-açúcar sobre essa região. Os resultados preliminares apontam que há uma competição no uso do solo na região que envolve Inhumas, Goiânia e outros municípios da Bacia do Rio Meia Ponte, pois o avanço das áreas plantadas de cana provoca mudanças nos arranjos produtivos locais, bem como, geram impactos socioeconômicos e ambientais de grande monta.
\end{abstract}

Palavras-chave: Cana-de-Açúcar, Gestão Territorial, Indústria Sucroalcooleira, Impactos Socioeconômicos e Ambientais.

\footnotetext{
${ }^{1}$ Prof. Dr. em Geografia do Instituto Federal de Educação, Ciência e Tecnologia-IFG-Campus Inhumas, Goiás. Doutorado em geografia, IESA-UFG-Instituto de Estudos Sócio-Ambientais (2012). Me. em Geografia, UFG (2005). Graduação em Geografia, Universidade Federal de Goiás-UFG (2003). Tem experiência na área de Geografia, com ênfase em Geografia Regional, Geografia do Município. Atua nos temas: Planejamento e gestão municipal, Estudos das paisagens urbanas-regionais, Educação ambiental, Zoneamento ecológico-econômico. É líder do Núcleo de Estudos e Pesquisas Interdisciplinares (NEPEINTER). E-mail: renatoaraujoifg@gmail.com ${ }^{2}$ Profa. Dra. em Matemática do Instituto Federal de Educação, Ciência e Tecnologia-Campus Inhumas, Goiás. Dra. em Ciências Ambientais, UFG (2009), Modelagem Matemática para Seleção de Áreas Prioritárias para Conservação. Me. em Matemática, Equações Diferenciais Parciais, UFG (2001). Graduação em Matemática, UFG (2000). Atua no ensino e pesquisa. Profa. do Mestrado em Tecnologias de Processos Sustentáveis e Mestrado em Educação Para Ciências e Matemática. E-mail: socorrodsc@ gmail.com
} 


\begin{abstract}
The Cerrado, the second largest biome in South America, covers an area of 2,039,387 km², covers 12 states, including the state of Goiás, and it is recognized as one of 34 biodiversity hotspots in the world, either by their aspects natural, as by intense agropastoril occupation that became the main Brazilian agriculture frontier expansion. The growing demand for alternative sources of renewable energy requires a rapid and poorly planned expansion, especially in areas occupied by savannah. In particular, the region of Meia Ponte River watersheds is distinguished by the complexity of this problem, which can result in significant negative consequences, either in the environmental area as in the socioeconomic. Thus, this article aims to present the main results of analyzes of the social, economic and environmental impacts caused by the intensification/expansion of sugar cane over this region. Preliminary results indicate that there is competition in land use in the region involving Inhumas, Goiânia and other municipalities in the Meia Ponte River basin, because the advancement of cane planted areas is causing changes in local clusters, as well as generating socioeconomic and environmental impacts of major consequence.
\end{abstract}

Key words: Sugarcane, Land Management, Sugar and Alcohol Industry, Socioeconomic and Environmental Impacts.

RESUMEN: El Cerrado, el segundo bioma más grande de América del Sur, tiene una superficie de 2.039.387 $\mathrm{km}^{2}$, abarca 12 estados, incluyendo el estado de Goiás, y es reconocido como uno de los 34 hotspots de biodiversidad en el mundo, ya sea por sus aspectos naturales, como por la intensa ocupación agropecuaria que se convirtió en la principal expansión de la frontera agrícola brasileña. La creciente demanda de fuentes alternativas de energía renovable requiere una expansión rápida y mal planeada, sobretodo en las zonas ocupadas por el bioma Cerrado. En particular, en la región de la bacía del Río Meia Ponte, se distingue por la complejidad de este problema, que puede resultar en significativas consecuencias negativas, tanto dentro del alcance ambiental cuanto socioeconómico. Por lo tanto, este artículo tiene como objetivo presentar los principales resultados del análisis de los impactos sociales, económicos y ambientales causados por la intensificación/expansión de la caña de azúcar en esta región. Los resultados preliminares indican que existe una competición en el uso del suelo en la región que abarca Inhumas, Goiânia y otros municipios de la cuenca del Río Meia Ponte, pues el avance de las superficies plantadas de caña provoca cambios en las agrupaciones locales, así como, generan impactos socioeconómicos y ambientales de grandes consecuencias.

Palabras-clave: Caña de azúcar, Ordenamiento Territorial, Industria de Azúcar y de Alcohol, Impactos Socioeconómicos y Ambientales.

\title{
INTRODUÇÃO
}

No atual cenário mundial de crise energética e ambiental, devido à tendência de escassez dos combustíveis fósseis, bem como, à emissão excessiva de gases que contribuem para o efeito estufa, vêm ocorrendo uma crescente demanda por fontes alternativas de energias renováveis e sustentáveis. Com isso emergem no cenário internacional os 
biocombustíveis, principalmente, aqueles derivados da cana-de-açúcar como mais prioritários e importantes para o mercado enérgetico.

O caso da produção canavieira no Brasil é uma resposta às necessidades dos mercados interno e externo. O território da cana-de-açúcar em Goiás configura-se de acordo com as investidas do capital no campo, em momentos históricos distintos.

Desse modo, os momentos históricos mais destacados no cultivo da cana-de-açúcar no Brasil foram: ${ }^{3}$ a) de 1975 a 1987, com a política do Proálcool, que teve como principal característica a rápida expansão produtiva de álcool e redução na produção do açúcar; b) de 1988 a 2000, houve a desregulamentação do setor canavieiro gerando crise e estagnação, ocasionando oscilações na produção tanto de álcool como de açúcar; c) de 2000 a 2011, ocorreu rápida expansão do setor sucroalcooleiro, em virtude do Plano Nacional de Energia (PNE) e, principalmente, pela demanda dos mercados interno e externo pelo etanol/combustível.

Ressalta-se que, apesar do reconhecimento dos benefícios econômicos e ambientais dos biocombustíveis, a sua expansão acelerada e não planejada poderá acarretar impactos negativos sobre a biodiversidade, tanto para os recursos hídricos quanto para a produção de alimentos.

$\mathrm{Na}$ atual conjuntura, o Brasil adotou o discurso de que será o país da transição energética do petróleo para o etanol. Entretanto, pouco se fala dos impactos ambientais e sociais oriundos da transformação da cana-de-açúcar em etanol para abastecer a demanda de mercado. Desde o plantio, passando pela queima, até chegar ao produto final (etanol nos postos), a cana gera grandes impactos tanto no ar, quanto na terra e na água. Segundo Aleixo (2007), para produzir-se 1 litro de etanol, é necessário cerca de 100 litros de água, dos quais 12 convertem-se em vinhoto. Considerando que o mundo deve produzir 147 milhões de toneladas de agrocombustíveis até 2030, serão produzidas mais de 2 bilhões de toneladas de água poluída.

No Brasil a demanda por biocombustíveis tem provocado uma expansão acelerada e pouco planejada do cultivo da cana-de-açúcar, principalmente em áreas do bioma Cerrado. $\mathrm{O}$ Cerrado é considerado um dos hotposts de biodiversidade no mundo, por ser uma área de alto endemismo de biodiversidade e de elevado estágio de degradação (MYERS et al., 2000; JHA et al., 2005). Além disso, é nele que se localiza grande parte das nascentes dos rios que

\footnotetext{
${ }^{3}$ Esta periodização do avanço e recuo da cultura canavieira no Brasil é de Castro et al. (2010, p. 176).
} 
integram algumas das principais bacias hidrográficas brasileiras (Araguaia-Tocantins, Paraná e São Francisco). Assim, a expansão acelerada e pouco planejada do setor sucroalcooleiro sobre o Cerrado é motivo de muita preocupação, pois poderá levar à extinção desse bioma único e de grande relevância ambiental.

Em relação ao estado de Goiás, que possui $97 \%$ de sua área inserida na região core do bioma Cerrado, essa preocupação ainda é maior, por constitui-se em uma das principais alternativas à expansão sucroalcooleira no Brasil (RIBEIRO, 2008). O bioma cerrado em função das suas características fisiográficas e desenvolvimento econômico, bem como, da infraestrutura implantada recetemente vem sendo bem degradado.

Sabe-se que na região da bacia do rio Meia Ponte, estudos revelam que se trata de uma área com alta degradação ambiental, que inclui a existência de pouquíssima cobertura vegetal, o comprometimento de sua biodiversidade e de seus recursos hídricos. Além disso, a ação antrópica, nessa região, é caracterizada, entre outras, pela grande concentração de áreas de cultivo de cana-de-açúcar, as quais se concentram, praticamente, ao longo da linha de drenagem do rio Meia Ponte (COUTO et al., 2011).

Neste contexto, este artigo faz uma análise exploratória mais detalhada dos impactos econômicos e sociais provocados pela intensificação/expansão da cana de açúcar sobre essa região, relacionando-a com os impactos ambientais. De fato, mesmo que o aumento da produção sucroalcooleira traga impactos positivos sobre o desenvolvimento econômico de uma região, por outro lado, devem ser considerados os impactos negativos tanto no âmbito ambiental, quanto no social. Impactos estes, que incluem a prática disseminada de queimadas para a colheita da cana-de-açúcar e demanda por novas áreas, que podem avançar sobre outras culturas e áreas de pastagens, ou mesmo sobre áreas de vegetação remanescentes (CASTRO et al., 2010). Esses fatores que refletem sobre a estrutura agrária e social da região como um todo. Segundo Groom e Gray (2007) existem a necessidade de políticas que minimizem esses impactos, visto que há poucas disposições legislativas, em nível global, voltadas ao ordenamento da expansão de áreas agrícolas para a produção de biocombustíveis.

Por fim, esse trabalho poderá contribuir na elaboração de políticas públicas, que minimizem os impactos negativos da expansão/intensificação da cana-de-açúcar e gere medidas mitigadoras ao desenvolvimento socioeconômico e ambiental, proporcionando um desenvolvimento mais sustentável para a região, caracterizada pela alta pressão antrópica e pela importância para o setor sucroalcooleiro do Estado de Goiás. 


\section{MATERIAL E MÉTODOS}

Este trabalho tem como área de estudo a região constituída pelos municípios de Itauçú, Inhumas, Brazabrantes, Nova Veneza, Goianira, Santo Antônio de Goiás e Goiânia, que fazem parte da bacia do rio Meia Ponte, caracterizados pelo avanço do front agrícola, representado, principalmente, pelo agronegócio da cana-de-açúcar, bem como, pelo processo de metropolização da capital goiana (figura 1).

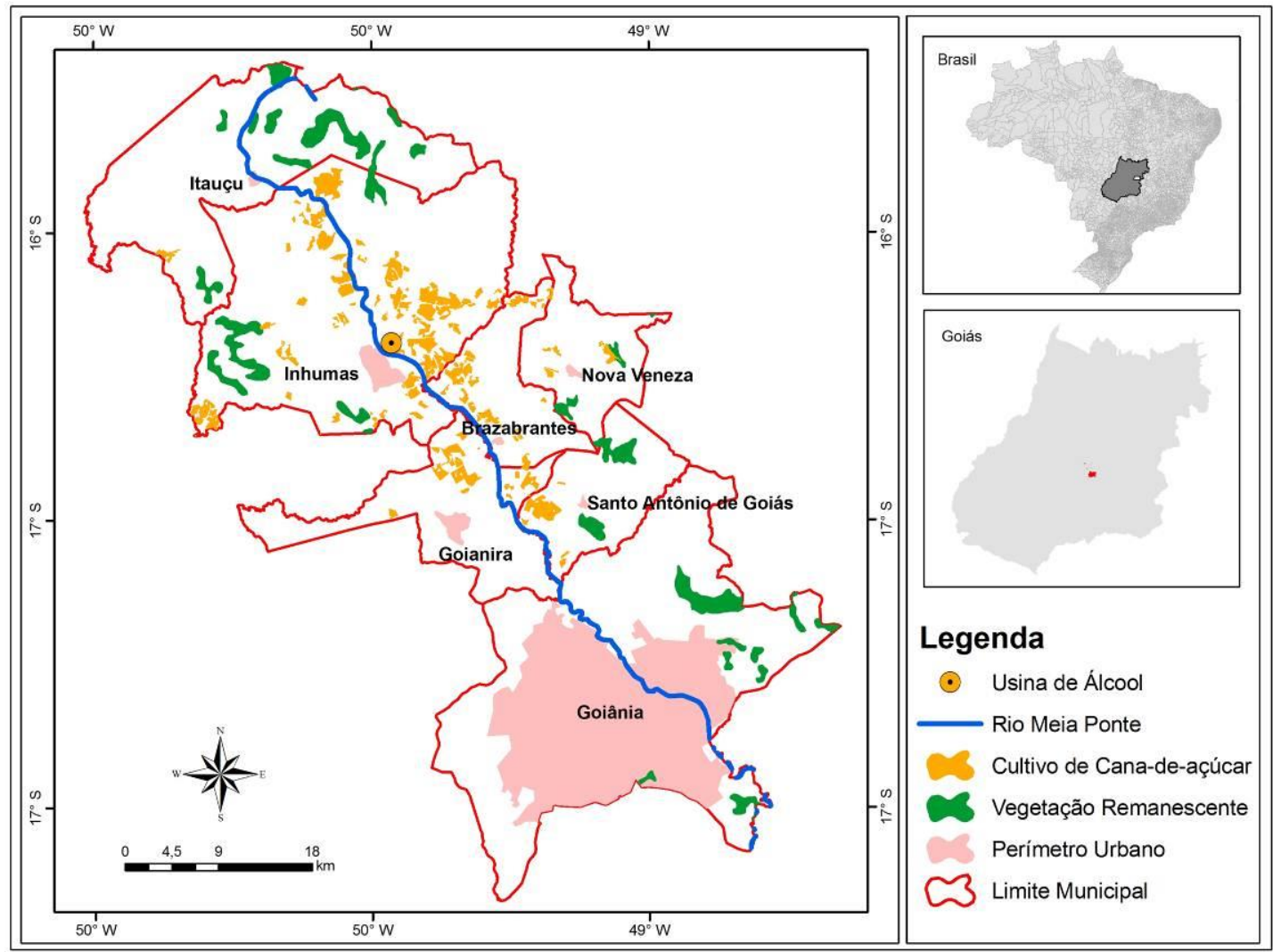

Figura 1. Área de Estudo: localização e distribuição de vegetação remanescente e de áreas de cana-de-açúcar. Organização: Couto (2012)

A pesquisa foi desenvolvida em dois momentos: no primeiro, a partir de um levantamento de dados do CANASAT, cartográficos, sociais e econômicos da área de estudo, seguida da análise e interpretação dos mesmos, por meio da apresentação de tabelas, gráficos e mapas; no segundo, a partir de um levantamento constituído por entrevistas semiestruturadas aos pequenos produtores e cortadores de cana na região de Inhumas. $\mathrm{O}$ conjunto de dados primários utilizados é detalhado através no esquema 1. 


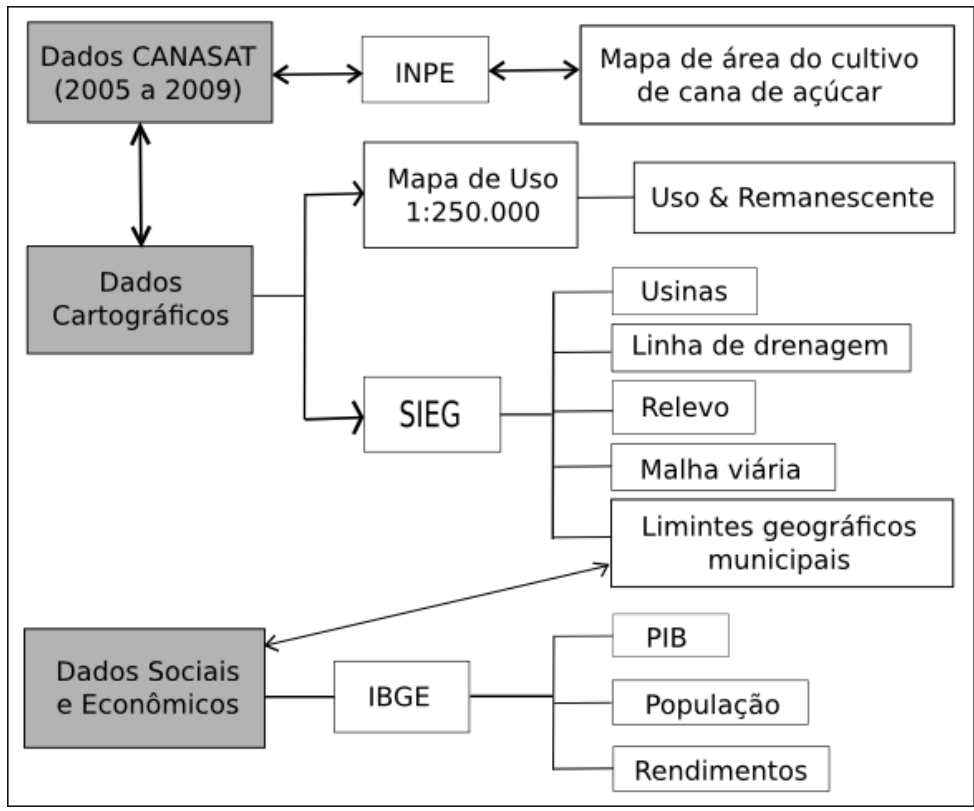

Esquema 1. Conjunto de dados primários aplicados na área de estudo. Organização: Couto (2012)

Os dados do CANASAT, projeto voltado ao mapeamento das áreas plantadas de canade-açúcar no país, foram produzidos pelo INPE (Instituto Nacional de Pesquisas Espaciais), a partir de imagens orbitais do satélite sino-brasileiro CBERS-2, referentes ao período de 2005 a 2009.

O conjunto de dados cartográficos e seus respectivos metadados (limites geográficos municipais, malha viária, usinas, declividade, linha de drenagem) utilizados neste trabalho, foram obtidos através do SIEG (Sistema Estadual de Estatística e de Informações Geográficas de Goiás). Quanto ao mapa de cobertura e uso da terra, foi obtido à escala de 1:250.000, a partir de interpretação de imagens $\mathrm{ETM}^{+}$dos anos de 2001 e 2002 e de levantamentos em campo, no âmbito do Projeto de Identificação de Áreas Prioritárias para Conservação da Biodiversidade no Estado de Goiás - PDIAP (SANO et al., 2008).

Os dados sociais e econômicos dos municípios incluíram população, rendimentos por domicílios e PIB foram obtidos por meio do IBGE (Instituto Brasileiro de Geografia e Estatística). Já os dados referentes à taxa de crescimento geométrico dos municípios produtores de cana-de-açúcar em Goiás foram obtidos da SEPIN-GO (Superintendência de Estatísticas, Pesquisa e Informações Socioeconômicas de Goiás).

Para fazer um estudo mais detalhado da relação espacial da cultura da cana-de-açúcar com a infraestrutura (usina, malha viária), relevo, uso da terra e o desenvolvimento 
socioeconômico da área de estudo foram utilizados diferentes funções topológicas, tais como: proximidade, interseção, união e extração de dados geograficamente referenciados.

\section{RESULTADOS E DISCUSSÕES}

A mundialização das economias e os avanços nos meios técnico-científicoinformacionais fizeram com que o meio ambiente fosse colocado na agenda das discussões de Estado. Sabe-se que o impacto no meio ambiente ou em algum de seus componentes é feito por determinada ação antrópica. Por outro lado, estas alterações precisam ser quantificadas, pois apresentam variações relativas, podendo ser positivas ou negativas, grandes ou pequenas.

As áreas plantadas com cana de açúcar foram analisadas em relação à distância da localização da usina sucroalcooleira do município de Inhumas em 2009. Observou-se que o crescimento da área total plantada ocorreu até um raio de $30 \mathrm{~km}$ da usina, conforme mostra no (gráfico 1), no qual há concentração mais destacada nos municípios de Inhumas e Brazabrantes.

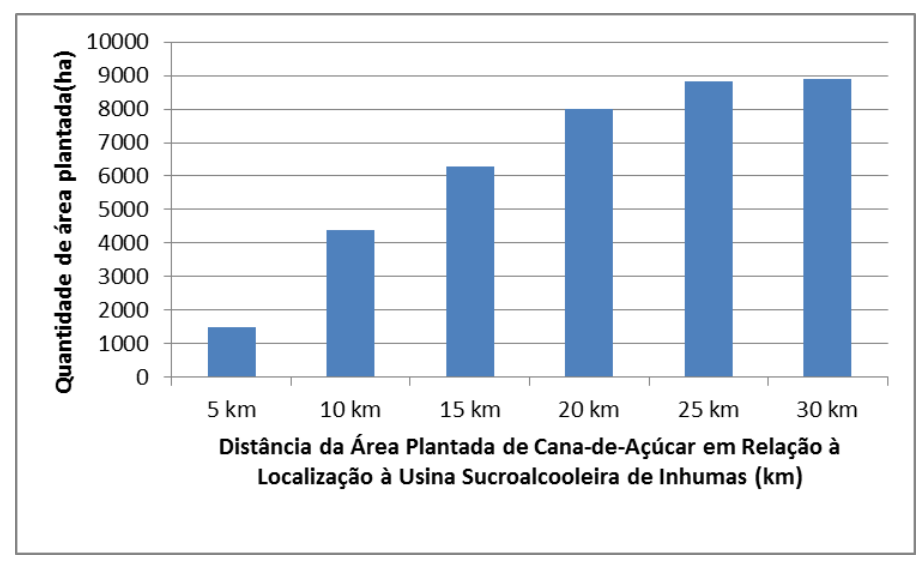

Gráfico 1. Quantidade de área plantada com cana-de-açúcar em relação à localização da usina sucroalcooleira do município de Inhumas no ano de 2009. Organização: Couto (2012)

Nas análises, também se observou que ocorreu um baixo aumento de áreas plantadas de cana entre 2008 a 2009, o que indica a tendência de estabilização do crescimento do setor sucroalcooleiro na região analisada conforme (gráfico 2). Isso se deve ao fato da saturação das áreas próximas à usina por outras atividades e a indisponibilidade de áreas apropriadas à mecanização (baixa declividade) 


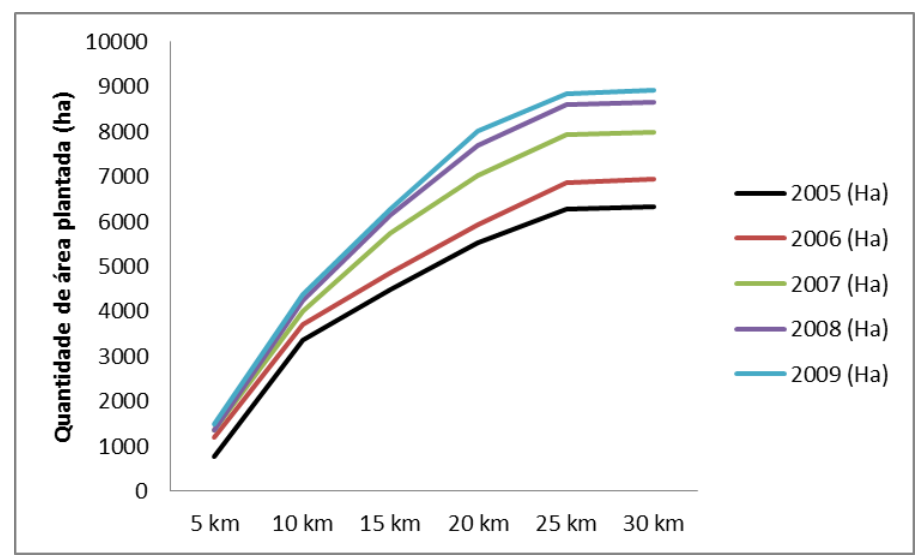

Gráfico 2. Distância da área plantada com cana-de-açúcar dentro da área de estudo em relação à usina no ano de 2005 a 2009. Organização: Couto (2012)

Pensava-se que as propriedades de terras em Inhumas eram em sua maioria latifúndios, mas a pesquisa qualitativa ${ }^{4}$ mostra que as maiores partes das terras arrendadas são oriundas de pequenas propriedades. Por isso que as lavouras de cana precisam, no plantio, criar outras frentes fora dos limites do município, ultrapassando o raio de $30 \mathrm{~km}$ exigidos para boa produtividade pelo teor de sacarose. Com isso, o território de Inhumas encontra-se em processo de disputa pelo uso do solo.

Os resultados das entrevistas semiestruturadas, realizadas nos dias 13/04/2010 e 15/04/2010, junto aos pequenos produtores e cortadores de cana na região de Inhumas, revelaram que a pequena propriedade está sendo incorporada à indústria canavieira. O Sr. Joaquim, de 70 anos, relata como se organizam os arrendamentos de terra nas redondezas do município de Inhumas:

Tudo aqui é arrendado, exceto ao lado da destilaria, 80 ha é próprio da usina no meio de 14 mil ha $^{5}$ que vai cortar esse ano. Não é praticamente nada, tudo é parceria agrícola que você paga para o parceiro no arrendamento da terra. $\mathrm{O}$ alqueire de terra dessa locação depende da distância da destilaria, das vias de acesso, do tamanho da

\footnotetext{
${ }^{4}$ Ver Teixeira (2013).

${ }^{5}$ A título de exemplificação, 1 ha equivale a $10.000 \mathrm{~m}^{2}$, já 1 alqueire goiano são $48.400 \mathrm{~m}^{2}$ ou 4,84 ha; 1 alqueire paulista vale $24.200 \mathrm{~m}^{2}$ ou $2,42 \mathrm{ha}$.
} 
terra. Aqui paga-se 60 a 90 toneladas por alqueire/ano que paga para o dono da terra (Inhumas, 15/04/2010 - transcrição livre).

O número de arrendamentos de terra é substancial, pois a usina possui apenas $0,5 \%$ de terras próprias para plantar cana-de-açúcar. Se não houvesse arrendamentos de terra, a indústria do etanol pararia, até porque o alqueire de terra na região do Mato Grosso Goiano é mais valorizado. Dependendo da região, estipula-se o valor na faixa entre 50 a 100 mil reais o alqueire em 2010, o que depende da localidade, declive do terreno, acessibilidade, entre outros fatores ${ }^{6}$.

O arrendamento de terras em Inhumas é uma questão conflituosa porque há diversos interesses econômicos e políticos escamoteados. É da terra que se mantém o exercício do poder local. Essa parte da pesquisa foi, sem dúvida, a mais tensa, porque, em vários momentos, na coleta de dados, ocorreram várias barreiras, tanto nas entrevistas com os cortadores de cana, quanto na coleta de dados com os donos da terra. Inclusive, muitos dados deixaram de ser colhidos, devido às influências das relações sociais em Inhumas serem constituídas de vínculos de amizade e laços familiares, os quais impediram o aprofundamento nessa temática.

Ressalta-se com o aumento do número de arrendamentos de terra para atender os interesses econômicos e políticos que norteiam a expansão da cana-de-açúcar em Inhumas, no período de 2005 a 2009, a área plantada com cana em um raio de $5 \mathrm{~km}$ da usina, praticamente, dobrou (gráfico 3).

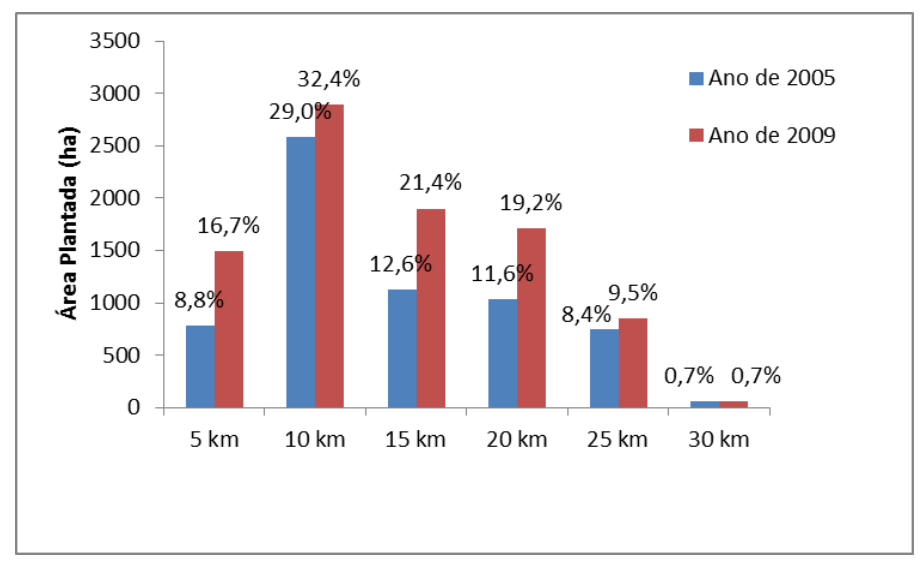

Gráfico 3. Quantidade de área plantada com cana-de-açúcar

\footnotetext{
${ }^{6}$ Idem (Teixeira, 2013).
} 


\section{em relação à localização da usina no ano de 2005 e 2009 (km) \\ Organização: Couto (2012)}

Pela imagem de uma fazenda e estudos feitos por (Teixeira, 2012) nos arredores de Inhumas, constata-se que a área arrendada é de 580,8 ha e uma área plantada de 312,7 ha, evidenciando que as lavouras de cana-de-açúcar avançam em áreas de pastagens, como mostra a figura 2.

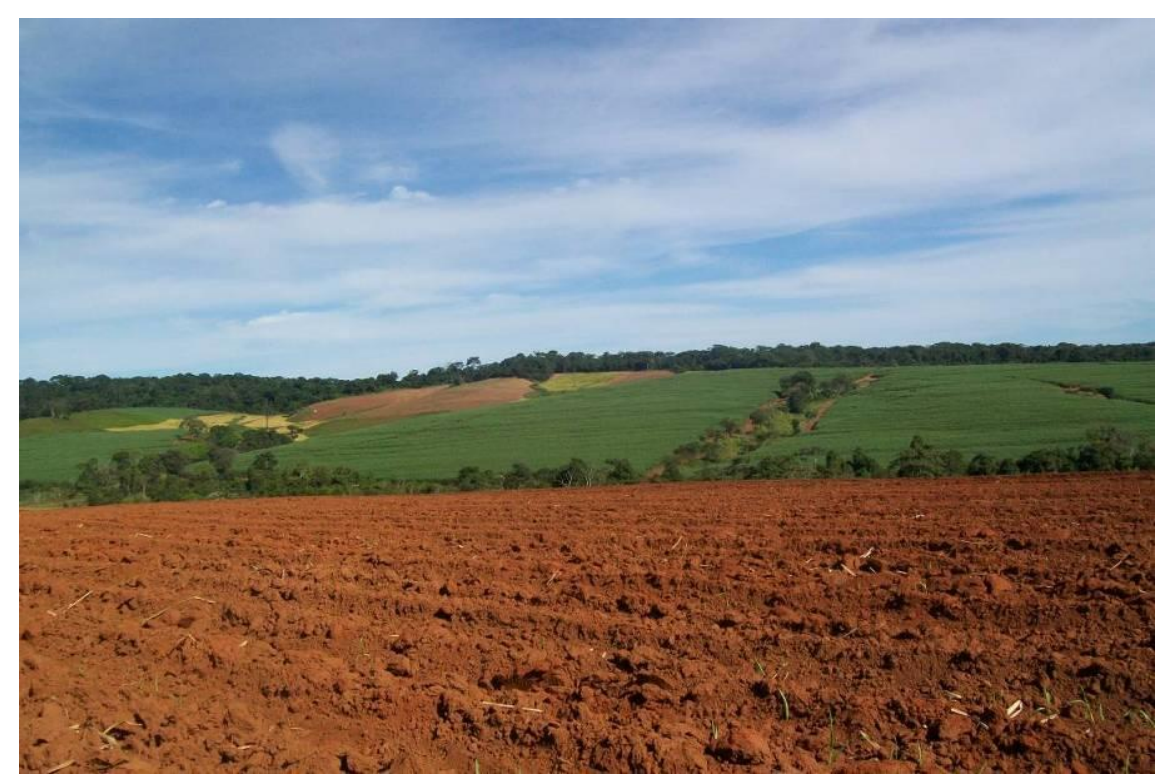

Figura 2. Fazenda arrendada nos arredores de Inhumas. Fonte: Teixeira (2012).

Analisando as áreas plantadas com cana-de-açúcar, em relação ao uso da terra com outras atividades agrícolas e com as áreas de pastagem, constata-se que, no período entre 2005 a 2009, a expansão da cana-de-açúcar, nas proximidades da usina, ocorreu sobre áreas agrícolas ocupadas com outras culturas e sobre as áreas de pastagem (figuras 3 e 4). 


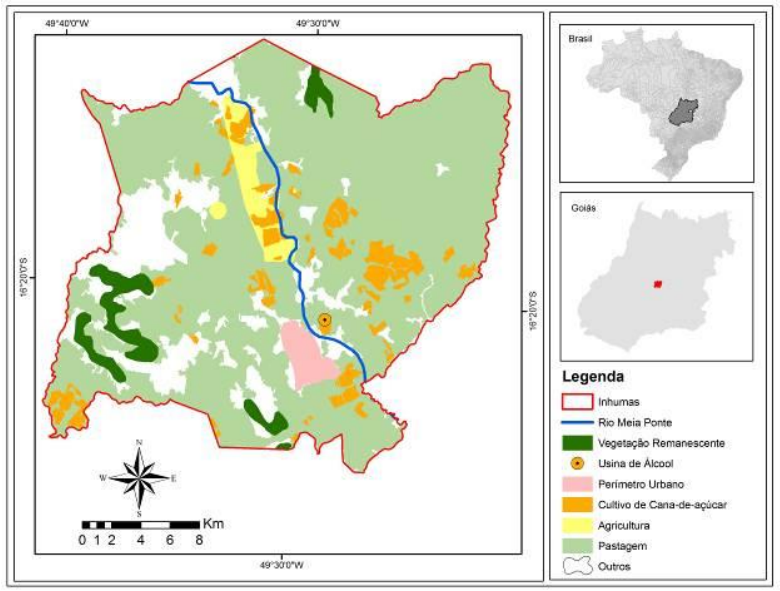

Figura 3. Distribuição das áreas de cana de açúcar no Município de Inhumas em 2005.

Organização: Couto (2012)

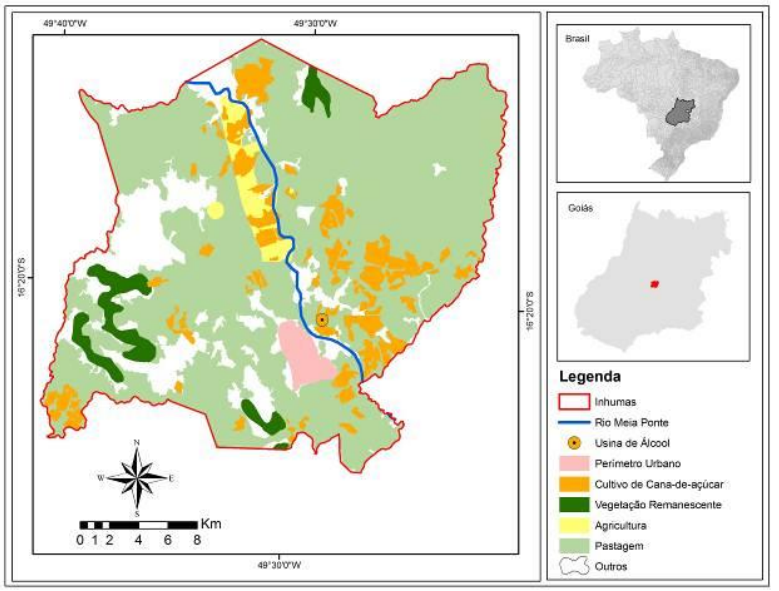

Figura 4. Distribuição das áreas de cana de açúcar no Município de Inhumas em 2009. Organização: Couto (2012)

Nessa análise, mostra-se que o percentual de áreas agrícolas ocupadas por outras culturas e de pastagem convertidas em áreas de cana nesse período, apenas no município de Inhumas, corresponde aproximadamente $10 \%$ e 3,5\%, respectivamente.

Em relação ao desenvolvimento econômico dos municípios do interior, dessa área de estudo, destaca-se, em todos os anos analisados, que o município de Inhumas é o maior PIB (gráfico 4), e, também, o único que contém a usina sucroalcooleira.

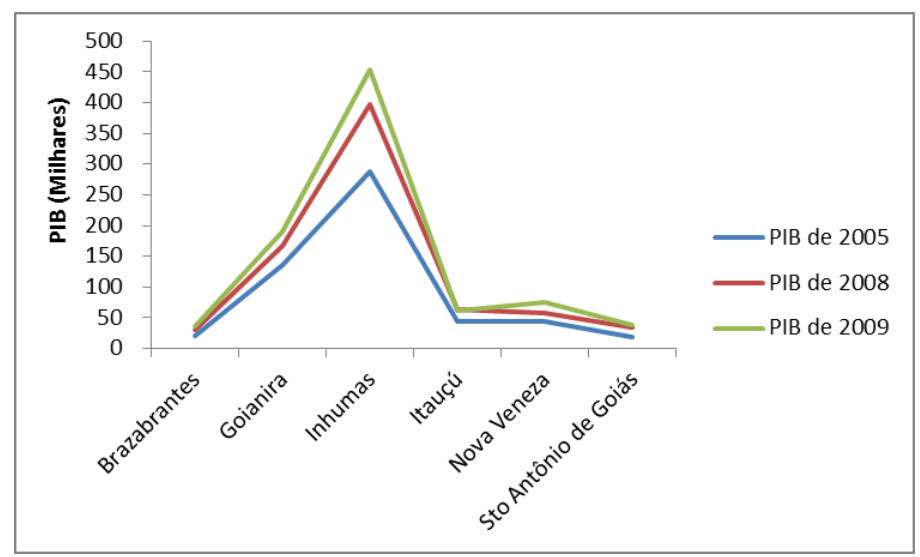

Gráfico 4. PIB dos municípios que compõe a área de estudo no período de 2005 a 2009.

Organização: Couto (2012).

Segundo as análises dos rendimentos por domicílio da área de estudo, o PIB não reflete sobre desenvolvimento econômico e social para a população, pois se constatou que, na maioria de seus municípios, mais de $60 \%$ da população ganham até um salário mínimo, inclusive Inhumas (gráfico 5). 


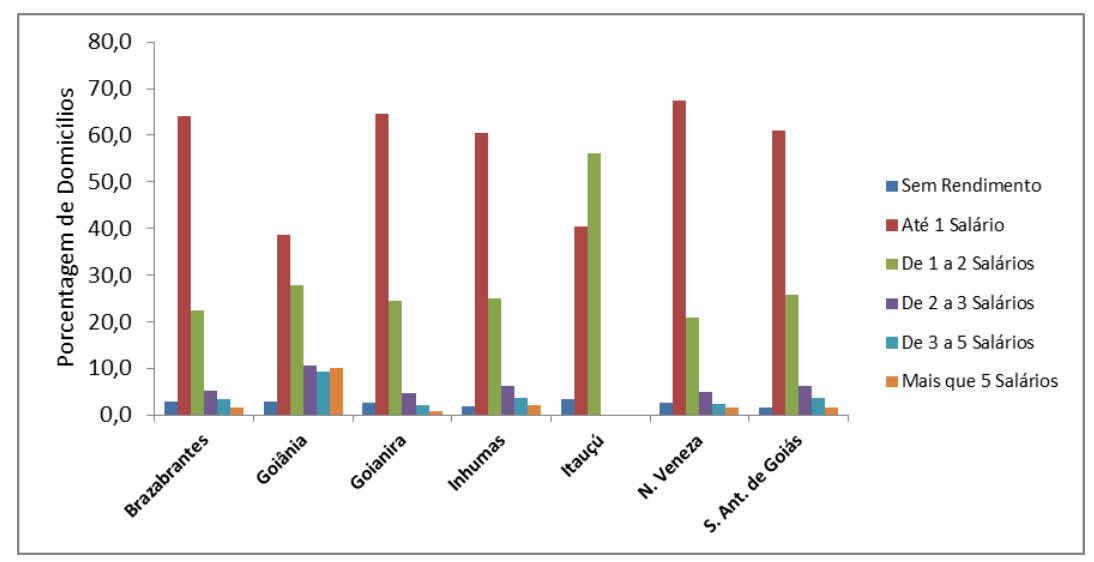

Gráfico 5. Rendimento por domicílios da área de estudo segundo o senso do IBGE de 2010.

Organização: Couto (2012)

Comparando a territorialização das destilarias a dados demográficos, temos um quadro preocupante. De acordo com Fernandes (2008), o território do agronegócio se distingue pela grande escala e homogeneidade da paisagem, caracterizado pela desertificação populacional, pela monocultura e pelo produtivismo para a exportação. Confira-se, no Quadro 1, a taxa geométrica de crescimento dos municípios produtores de cana-de-açúcar em Goiás.

Quadro 1. Taxa de crescimento geométrico dos municípios produtores de cana-de-açúcar, Goiás (2000-2008). 
ANÁLISE DOS IMPACTOS SOCIOECONÔMICOS E AMBIENTAIS DA EXPANSÃO DA CANA-DE-AÇÚCAR NA BACIA DO RIO MEIA PONTE, GOIÁS.

DOI: $10.5216 /$ teri.v3i1.27336

\begin{tabular}{|c|c|c|c|c|c|c|c|c|}
\hline \multirow{3}{*}{ MUNICÍPIOS } & \multirow{3}{*}{$\begin{array}{c}\text { Situação da } \\
\text { empresa }\end{array}$} & \multicolumn{4}{|c|}{ Total da produção canavieira em Ton. } & \multirow{3}{*}{$\begin{array}{c}\text { Total da } \\
\text { população } \\
\text { (2000) }\end{array}$} & \multirow{3}{*}{$\begin{array}{c}\text { Total da } \\
\text { população } \\
\text { (2008) }\end{array}$} & \multirow{3}{*}{$\begin{array}{c}\text { Taxa } \\
\text { geométrica } \\
\text { de } \\
\text { crescimento } \\
(2000-2008)\end{array}$} \\
\hline & & \multicolumn{2}{|c|}{2000} & \multicolumn{2}{|c|}{2008} & & & \\
\hline & & $\begin{array}{l}\text { Área } \\
\text { (ha) }\end{array}$ & Ton. & $\begin{array}{l}\text { Área } \\
\text { (ha) }\end{array}$ & Ton. & & & \\
\hline Acreúna & $\begin{array}{l}\text { Em operação } \\
\text { (2008) Previsão de } \\
\text { produção em } 2009 \\
\text { (01) }\end{array}$ & 8.620 & 689.600 & 10.540 & 948.600 & 18.301 & 19.173 hab. & $0,58 \%$ \\
\hline Anicuns & Operação (01) & 5.498 & 480.000 & 9.805 & 794.205 & 18.754 & 18.110 hab. & $-0,44 \%$ \\
\hline Aporé & $\begin{array}{l}\text { Previsão de } \\
\text { produção em } 2010\end{array}$ & - & - & 820 & 49.200 & 3.427 & 3.684 hab & $0,91 \%$ \\
\hline Cachoeira Alta & $\begin{array}{l}\text { Em implantação } \\
\text { (01) }\end{array}$ & - & - & 600 & 51.000 & 8.646 & 8.280 hab & $-0,54 \%$ \\
\hline $\begin{array}{l}\text { Cachoeira } \\
\text { Dourada }\end{array}$ & Projeto (01) & - & - & 3.000 & 240.000 & 8.525 hab & 7.666 hab & $-1,32 \%$ \\
\hline Caçu & Projeto (01) & - & - & 4.700 & 423.000 & $10.575 \mathrm{hab}$ & $11.281 \mathrm{hab}$ & $0,81 \%$ \\
\hline $\begin{array}{l}\text { Carmo do Rio } \\
\text { Verde }\end{array}$ & Operação (01) & 1.200 & 90.000 & 7.000 & 525.000 & $7.941 \mathrm{hab}$ & $9.333 \mathrm{hab}$ & $2,04 \%$ \\
\hline $\begin{array}{l}\text { Chapadão do } \\
\text { Céu }\end{array}$ & $\begin{array}{l}\text { Previsão de } \\
\text { produção em } 2009\end{array}$ & - & - & - & - & $3.778 \mathrm{hab}$ & 5.673 hab & $5,21 \%$ \\
\hline Edéia & $\begin{array}{l}\text { Em operação } \\
(2008)(01)\end{array}$ & - & - & 12.000 & 960.000 & $10.223 \mathrm{hab}$ & 10.577 hab & $0,43 \%$ \\
\hline Goiatuba & Operação (01) & 5.244 & 411.420 & 18.600 & 1.525 .200 & $31.130 \mathrm{hab}$ & $32.220 \mathrm{hab}$ & $0,43 \%$ \\
\hline Goianésia & $\begin{array}{l}\text { Projeto (01) } \\
\text { Operação (02) }\end{array}$ & 13.000 & 1.040 .000 & 13.500 & 1.147 .500 & 49.160 hab & 56.169 hab & $1,68 \%$ \\
\hline Gouvelândia & Projeto (01) & - & - & 16.000 & 1.600 .000 & $4.009 \mathrm{hab}$ & $4.721 \mathrm{hab}$ & $2,06 \%$ \\
\hline Inaciolândia & Projeto (01) & 130 & 8.450 & 3.270 & 262.950 & $5.239 \mathrm{hab}$ & $5.887 \mathrm{hab}$ & $1,47 \%$ \\
\hline Inhumas & Operação (01) & 3.600 & 260.000 & 6.000 & 480.000 & $43.897 \mathrm{hab}$ & $46.555 \mathrm{hab}$ & $0,74 \%$ \\
\hline Ipameri & Operação (01) & 5.000 & 250.000 & 3.040 & 243.200 & $22.628 \mathrm{hab}$ & $23.911 \mathrm{hab}$ & $0,69 \%$ \\
\hline Itapaci & Operação (01) & 40 & 2.000 & - & - & $13.931 \mathrm{hab}$ & $16.806 \mathrm{hab}$ & $2,37 \%$ \\
\hline Itapuranga & Operação (01) & 20 & 800 & 9.500 & 855.000 & $26.740 \mathrm{hab}$ & $25.337 \mathrm{hab}$ & $-0,67 \%$ \\
\hline Itarumã & $\begin{array}{l}\text { Previsão de } \\
\text { produção em } 2010\end{array}$ & - & - & - & - & 5.446 hab & 5.491 hab & $0,10 \%$ \\
\hline Itumbiara & $\begin{array}{l}\text { Previsão de } \\
\text { produção em } 2009\end{array}$ & 5.977 & 418.390 & 15.130 & 1.212 .800 & $81.430 \mathrm{hab}$ & $91.843 \mathrm{hab}$ & $1,52 \%$ \\
\hline Jandaia & Operação (01) & 9.690 & 823.650 & 10.800 & 799.200 & $6.342 \mathrm{hab}$ & $6.578 \mathrm{hab}$ & $0,46 \%$ \\
\hline Jataí & Projeto (01) & 60 & 1.500 & 1.000 & 140.000 & 75.451 hab & 85.491 hab & $1,57 \%$ \\
\hline Mineiros & Projeto (01) & 15 & 600 & 6.535 & 359.425 & $39.024 \mathrm{hab}$ & $47.500 \mathrm{hab}$ & $2,49 \%$ \\
\hline Montividiu & $\begin{array}{l}\text { Previsão de } \\
\text { produção em } 2009\end{array}$ & - & - & 3.200 & 320.000 & 7.736 hab & 9.766 hab & $2,96 \%$ \\
\hline Morrinhos & $\begin{array}{l}\text { Previsão de } \\
\text { produção em } 2009\end{array}$ & - & - & - & - & $36.990 \mathrm{hab}$ & $40.512 \mathrm{hab}$ & $1,14 \%$ \\
\hline Paraúna & $\begin{array}{l}\text { Previsão de } \\
\text { produção em } 2009\end{array}$ & 120 & 1.680 & 100 & 3.600 & $10.834 \mathrm{hab}$ & 11.283 hab & $0,51 \%$ \\
\hline Pontalina & $\begin{array}{l}\text { Previsão de } \\
\text { produção em } 2010\end{array}$ & - & - & 400 & 32.000 & 16.556 hab & $16.688 \mathrm{hab}$ & $0,10 \%$ \\
\hline Porteirão & Operação (01) & 1.143 & 74.295 & 21.500 & 1.763 .000 & $2.823 \mathrm{hab}$ & $3.129 \mathrm{hab}$ & $1,29 \%$ \\
\hline Quirinópolis & Operação (01) & - & - & 25.000 & 2.400 .000 & $36.512 \mathrm{hab}$ & $39.485 \mathrm{hab}$ & $0,98 \%$ \\
\hline Rio Verde & Operação (01) & 4.000 & 320.000 & 6.700 & 589.600 & $116.552 \mathrm{hab}$ & $158.818 \mathrm{hab}$ & $3,94 \%$ \\
\hline Rubiataba & Operação (01) & 2.100 & 157.500 & 7.000 & 560.000 & $18.087 \mathrm{hab}$ & $18.583 \mathrm{hab}$ & $0,34 \%$ \\
\hline $\begin{array}{l}\text { Santa Helena } \\
\text { de Goiás }\end{array}$ & Operação (01) & 15.762 & 1.260 .960 & 30.000 & 2.550 .000 & 34.545 hab & 36.198 hab & $0,59 \%$ \\
\hline $\begin{array}{l}\text { Santo Antônio } \\
\text { da Barra }\end{array}$ & Projeto (01) & 410 & 32.800 & 700 & 59.500 & $4.052 \mathrm{hab}$ & 4.276 hab & $0,67 \%$ \\
\hline São Simão & $\begin{array}{l}\text { Em operação } \\
(2008)(01)\end{array}$ & - & - & 2.400 & 264.000 & $13.552 \mathrm{hab}$ & $14.308 \mathrm{hab}$ & $0,68 \%$ \\
\hline Serranópolis & $\begin{array}{l}\text { Em implantação } \\
\text { (01) }\end{array}$ & - & - & 7.126 & 605.710 & $6.447 \mathrm{hab}$ & $7.692 \mathrm{hab}$ & $2,23 \%$ \\
\hline Silvânia & $\begin{array}{l}\text { Previsão de } \\
\text { produção em } 2009\end{array}$ & 70 & 1.400 & 55 & 1.950 & $20.339 \mathrm{hab}$ & 19.038 hab & $-0,82 \%$ \\
\hline Turvelândia & Operação (01) & 15.395 & 986.050 & 11.700 & 877.500 & 3.524 hab & 4.020 hab & $1,66 \%$ \\
\hline Uruaçu & $\begin{array}{l}\text { Em operação } \\
(2008)(01)\end{array}$ & 85 & 3.400 & 1.740 & 107.880 & $33.530 \mathrm{hab}$ & 34.411 hab & $0,32 \%$ \\
\hline Vicentinópolis & $\begin{array}{l}\text { Em operação } \\
(2008)(01)\end{array}$ & - & - & 10.000 & 780.000 & $6.015 \mathrm{hab}$ & $6.091 \mathrm{hab}$ & $0,16 \%$ \\
\hline Vila Boa & Operação (01) & 30 & 900 & 3.012 & 240.360 & $3.287 \mathrm{hab}$ & $4.461 \mathrm{hab}$ & $3,89 \%$ \\
\hline $\begin{array}{l}\text { TOTAL DA } \\
\text { REGIÃOO }\end{array}$ & 40 & 97.209 & 7.315 .395 & 282.473 & 23.531 .260 & 868.978 & 971.075 & \\
\hline $\begin{array}{l}\text { TOTAL DO } \\
\text { ESTADO }\end{array}$ & 59 & 139.186 & 10.162 .959 & 403.970 & 33.359.559 & 5.003 .228 & 5.844 .996 & $1,96 \%$ \\
\hline
\end{tabular}

Fonte: SEPLAN-GO (2010) Organização: Teixeira (2012). 
O quadro 1 mostra que, dos 39 municípios que possuem destilarias no estado de Goiás: a) cinco municípios tiveram crescimento populacional negativo; b) 18 municípios tiveram crescimento populacional $<1,0 \%$; c) sete municípios tiveram crescimento populacional $<2,0 \%$; d) 6 municípios tiveram crescimento populacional $<3,0 \%$; e) dois municípios tiveram crescimento populacional $<4,0 \%$;) nenhum município teve crescimento populacional $<5,0 \%$; g) um município teve crescimento populacional $<6,0 \%$.

Assim, o território da cana-de-açúcar em Goiás configura-se de acordo com as investidas do capital no campo, em momentos históricos distintos, podendo com isso, interferir nos arranjos produtivos locais, bem como, no processo demográfico onde esteja instalada uma dada destilaria.

\section{CONSIDERAÇÕES FINAIS}

Ressalta-se que a dinâmica exploratória do solo inhumense, a partir da cana-de-açúcar, trouxe impactos diversos tanto sociais quanto ambientais, tais como:

1. maior exploração da mais valia do trabalhador, ocasionando precarização das condições de trabalho;

2. impactos ambientais de todas as ordens, seja no ar (queimadas), solos (erosões, lixiviações) ou água (contaminação dos lençóis freáticos);

3. arrendamentos de terra que expropriam o pequeno produtor do campo.

Constatou-se que a destilaria de Inhumas, além de desarticular o seu território, abala os municípios vizinhos, porque contrata e arrenda produtores para a produção de cana. Essa produção é beneficiada em Inhumas e não em Itauçú, Brazabrantes, Nova Veneza, Goianira e Santo Antônio de Goiás. Portanto, deve haver uma política nacional para o setor sucroalcooleiro no Brasil e, principalmente, em Goiás.

Vale lembrar que, na década de trinta, tentou-se uma política nacional de aproximar o sertão atrasado do litoral moderno - a Marcha para o Oeste. Agora ostentam uma Marcha da Cana em que utilizam o cerrado já modernizado e com técnicas avançadas de manejo para transformar o que restou de cerrado em um mar de cana-de-açúcar. Nesse ritmo de maximização e exploração das terras goianas, é possível que o sertão vire mar de cana ?. E, mais uma vez, quem pagará a conta do modelo de desenvolvimento econômico e energético 
serão o cerrado e os goianos. Como diria na música "Sobradinho”, do Trio Nordestino: “o sertão vai virar mar, dá no coração, o medo que algum dia, o mar também vire sertão"...

Como já foi dito, nem sempre o acúmulo financeiro de um município representa qualidade de vida para sua população. Foi constatado, nessa pesquisa, que a região de Inhumas é uma das glebas mais valorizadas do estado, porque seu território está totalmente inserido na mancha de terra roxa, com grande teor de fertilidade natural. Isso explica o fato de a maioria das terras serem arrendadas e as lavouras de cana terem alta produtividade, uma das maiores do Brasil. O solo urbano é muito valorizado, o preço de um lote na periferia de Inhumas compra até 2 lotes em Brazabrantes e 2,5 em Goianira. Esse aspecto ajuda a impedir que Inhumas se transforme num reduto de especuladores imobiliários ou até mesmo numa cidade dormitório de Goiânia.

Os resultados apresentados, neste trabalho, sugerem ainda a necessidade de se desenvolver novas pesquisas para os reflexos do mar de cana no front da metrópole, desencadeando novos olhares e novas abordagens. Essa particularidade do município de Inhumas em fazer parte de uma região metropolitana, tendo como centro econômico uma destilaria de etanol, propicia um estudo singular no contexto regional goiano.

\section{AGRADECIMENTOS}

Este trabalho contou com o apoio do Programa de Apoio à Produtividade em Pesquisa PROAPP/IFG.

\section{REFERÊNCIA BIBLIOGRÁFICA}

ALEIXO, J. O agrocombustível ameaça a agricultura familiar e solidária. IBASE, 2007. Disponível em: <www.ibase.org.br>. Acesso em: 16 fev.2010.

CASTRO, S. S.; ABDALA, K.; SILVA, A. A.; BORGES, V. A Expansão da Cana-de-Açúcar no Cerrado e no Estado de Goiás: Elementos para uma Análise Espacial do Processo. Boletim Goiano de Geografia (Revista Eletrônica) Goiânia: IESA/UFG, v.30, n.1, 2010, p. 171-190.

COUTO, M. S. D. S.; SMITH, O. P.; TEIXEIRA, R. A. Modelagem Matemática para Seleção de Áreas Prioritárias para Conservação ou Restauração no Cerrado Goiano. Mercator, v.10, n.23, 2011, p. 225-236.

FERNANDES, B.M. Entrando nos territories do território. In: Campesinato e territórios em disputa. São Paulo: Expressão Popular, 2008, p.273-301. 
GROOM, J. M.; GRAY, M. E. Townsend A. P. Biofuels and Biodiversity: Principles for Creating Better Polices for Biofuel Production. Conservation Biology, v. 22, n.3, 2007, p. 602-609.

JHA, C. S.; GOPARAJU, L.; TRIPATHI, A.; GUARAI, B.; RAGHUBANSHI, A. S.; SINGH, J. S. Forest fragmentation and its impact on species diversity: an analysis using remote sensing and GIS. Biodiversity and Conservation, v. 14, 2005, p. 681-1698.

MYERS, N.; MITTERMEIER, R. A.; MITTERMEIER, C. G.; FONSECA, G. A. B.; KENT, J. Biodiversity hotspots for conservation priorities. Nature, n. 403, 2000, p. 853-858.

RIBEIRO, N. V.; FERREIRA JÚNIOR, L. G.; FERREIRA, N. C. Expansão do Setor Sucroalcooleiro no Cerrado Goiano: Cenários Possíveis e Desejados. In: IX SIMPÓSIO NACIONAL DO CERRADO E II SIMPÓSIO INTERNACIONAL DE SAVANAS TROPICAIS. Anais. Brasília: Embrapa, 2008. 1 Disponível em: http://<simposio.cpac.embrapa.br/simposio/trabalhos_pdf/00489_trab1_ap.pdf >. Acesso em: 04/01/2011.

SANO, E. E.; ROSA, R.; BRITO J. L.; FERREIRA, L. G. Mapeamento semidetalhado (escala de 1:250.000) da cobertura vegetal antrópica do bioma Cerrado. Pesquisa Agropecuária Brasileira, n. 43 (1), 2008, p. 153-156.

TEIXEIRA, R. A. Município de Inhumas: com eira e sem beira no descompasso da metrópole. Tese (Doutorado em Geografia) - Instituto de Estudos Sócio-ambientais, Universidade Federal de Goiás, Goiânia, 2012.

. Renato Araújo. No descompasso da metrópole. Um estudo sobre a dinâmica espacial da região metropolitana de Goiânia a partir do município de Inhumas. Goiânia: editora IFG, 2013. 